\title{
Uncanny Bodies. The Coming of Sound Film and the origins of the Horror Genre
}

Anneleen Masschelein

\author{
Robert Spadoni, \\ Uncanny Bodies. The Coming of Sound Film and \\ the origins of the Horror Genre. \\ Berkeley/Los Angeles/London: University of \\ California Press, 2007. 190 pages.
}

ISBN: 978-0-520-25122-9

Uncanny Bodies is a subtle and revealing study of the transition era between the silent film and the sound film, more specifically the period between 1926 until about 1931. Spadoni gives an original twist to his subject, that has been well examined from different perspectives, by meticulously focusing on two horror films, both from 1931, Tod Browning's Dracula and James Whale's Frankenstein. Spadoni foregrounds the notion of 'the uncanny body' in the transition era of the sound film to indicate the ghostlike, eerie impression made by human figures in early sound films on viewers that were still accustomed to the conventions of silent movies. The human figure in those films is uncanny in Freudian terms: the actors give a disturbing impression of being ghostlike or artificial, hovering between life and death, between animated and the inanimate, between human and inhuman. The hypothesis is in the first place based on the contemporary reception of early sound films, that is well documented with extensive quotes not only from film criticism of the period, but also references to other documents such as the film editing script of Dracula. Especially in the case of Dracula the contrast between the contemporary reception and later critical assessments is striking.

Spadoni takes care to argue his thesis by incorporating various factors ranging from technological aspects (sound, camera, and lighting) to acting techniques (from expressionist film to theatre), diction, make-up and setting. Whereas film history tends to see the evolution of silent film to sound film in terms of increasing realism, Spadoni shows how in the transition period the sound film came across as 'unnatural', contrived, somehow foregrounding the unrealistic character of the movie and of the medium. This unrealistic quality is especially linked to human figures that are regarded as grotesque and 'bloodless'. This is, according to the contemporary criticism, caused by the close-ups of the speaking actors that are 
mismatched with clumsily synchronized sounds, by the tin quality of the sound and by the overall poor quality of the sound installation. As a result, the human voice was not perceived as coming from the actors' mouth but as coming from somewhere else, heightening the unnatural quality of their appearance resulting in the impression of 'talking shadows'. The addition of sound thus paradoxically initially emphasized the artificiality of cinema rather than producing a more encompassing and therefore more realistic representation of human experience due to several factors: the primitive technology, the lack of narrative codes to integrate sound in storytelling on the part of filmmakers and the unfamiliarity of viewers to the conventions of sound film. Two genres successfully emerged from this transition period, the musical and the horror film, because they knew how to deploy this artificiality.

The main part of Uncanny Bodies is devoted to Dracula, one of the first successful Universal horror sound films, that appeared by the end of the transition period. Contrary to Whale's Frankenstein, which is still regarded as a classic of the horror genre and which has retained its disturbing powers, the reception of Dracula has significantly changed in later years. Whereas later viewers see the film as dated and seriously marred in various respects - a camp classic at best - the overriding view at the time was different. The film was both a commercial and a critical success and, as Spadoni demonstrates, the film was lauded precisely on grounds that are later detracted, i.e. its realism and the overall successful horror strategies that it deploys. Spadoni examines this critical gap in a very thorough analysis of the film and concludes that Dracula's achievement at the time is intricately related to the moment of its appearance on the cusp of the transition to sound film. Dracula's strength is that it manages to use the uncanny aspects of the early sound film, integrating them in the story and in the character of Dracula, the undead. Indeed, Bela Lugosi's diction, appearance and voice double the uncanny appearance of human figures in sound films. Moreover, the use of sound and especially silence (the early sound films did not yet use extradiegetic sounds or a soundtrack) paradoxically heightens the realistic or naturalist quality of the film for a contemporary audience and effectively produces terrifying effects. Thus, Dracula can be regarded not just as a genre film, but also as a filmic commentary on and a working through of the transition from silent film to sound film. However, once this context is lost for viewers, the film also loses its effect and is perceived as unnatural and forced. Dracula is in this sense a fortunate coincidence and the film retains its status as one of the originators of the horror genre mainly 
by the grace of more accomplished successors, like Frankenstein, that demonstrate that the techniques deployed by Dracula were not merely a matter of chance.

Frankenstein also foregrounds the uncanny body of a creature that is neither dead nor alive in the story as well as in the character and in the setting. Boris Karloff's embodiment of the monster flaunts its artificiality, for instance through the artful make-up, in the sound effects (the monsters growls) but also in the studio's marketing. In this way, the film achieves a timeless quality and continues to produce horror effects to this day. Although Spadoni's analysis of Frankenstein is less elaborate than that of Dracula, his discussion of both films as the doubled origin of the horror genre is very convincing. The horror film is not merely dependent on the studio or on the sound film per se, but effectively hinges on the transition between silent film and sound film that entails technical innovations, but also adaptations on the side of producers and audience in an interval of temporarily heightened awareness of the medium itself. Spadoni ends rather abruptly with two short analyses of further horror films the independent White Zombie (Victor Halperin) and Universal's The Mummy (Karl Freund), where I would have preferred a more theoretical elaboration of his genealogy of the horror genre. Overall, however, this is an erudite study that stimulates questions about other transition periods and about the complex relation between technology, narrative and reception. The analysis of Dracula is very comprehensive but despite the details Spadoni never lets his subject disappear in vague claims or theoretical jargon, which is a great merit of the book that is a pleasure to read. With his central notion of the uncanny body, Spadoni remains close to the Freudian uncanny without entering into the ramifications of the concept in the last twenty years (apart from brief references to Terry Castle and Nicholas Royle - other sources might have been useful and topical) but his focus on the human figure in early sound film as a combination between image, sound, actor and acting styles makes his application of the concept original and stimulating.

Anneleen Masschelein is research fellow of FWO Vlaanderen and teaches at the Faculty of Arts of the KU Leuven. She is also editor of Image (\&) narrative.

Email: Anneleen.masschelein@arts.kuleuven.be 